\title{
GESAMTINHALTSVERZEICHNIS zu Band I und II
}

Einleitung des Herausgebers . . . . . . . . . XII

1. Die Notwendigkeit einer Neuausgabe . . . . . . . . . XII

II. Die Entstehung der Glaubenslehre Schleiermachers. . . . . . XV

III. DieWürdigung und Kritik derGlaubenslehre im Neuprotestantismus XXXI

IV. Zur Einrichtung von Text und Apparat. ........ XLI

V. Verzeichnis der Abkürzungen ........... XLII

ERSTER BAND

Tieal ... . . . . . . . . . . . . . . . . . . . . I

Vorrede . . . . . . . . . . . . . . . . . . . . 3

Inhalt . . . . . . . . . . . . . . . . . . . . . ,

Einleitung. . . . . . . . . . . . . . . . . . . 8

Erklărung ...................... 8

Erstes Kapitel: Zur Erklärung der Dogmatik $\int_{2-19} . . .10$

Einleitung 52 .................... 10

I. Zum Begrifl der Kirche. Lehnsätze aus der Ethik $\int_{3}-6$. . 14

II. Von den Verschiedenheiten der frommen Gemeinsehaften uberhaupt. Lehnsätze aus der Religionsphilosophie $\left\{\begin{array}{lll}7-10 & 47\end{array}\right.$

III. Darstellung des Christentums seinem eigentümlichen Wesen nach. Lehnsătze aus der Apologetik $911-14$. . . . . . 74

IV. Vom Verhältnis der Dogmatik zur christlichen Frömmigkeit 515-19.................... 10s

Zweites Kapitel: Von der Methode der Dogmatik $\oint_{20-31} 125$

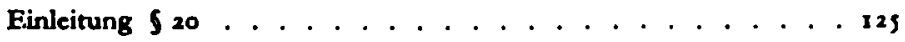

I. Von der Aussonderung des dogmatischen Stoffs $21-26,127$

II. Von der Gestaltung der Dogmatik $\$ 27^{\circ}-31$. . . . . . $14^{8}$

DER GLAUBENSLEHRE ERSTER TEIL

Entwicklung des frommen Selbstbewußtseins, wie es in jeder christlich frommen Gemütserregung immer schon vorausgesetzt wird, aber auch immer mit enthalten ist $\S_{32}-6_{1} \ldots \ldots \ldots \ldots$ 
Erster Abschnitt: Beschreibung unseres frommen SelbstbewußBtseins, sofern sich darin das Verhältnis zwischen der Welt und Gott ausdrückt $\$ 36-49 \ldots \ldots$. . .

Einleitung $\$ 36-39 \ldots \ldots$. . . . . . . . . 18\$

Erstes Lehrstück: Von der Schöpfung $\$ 40-41 . . . . . . . . ~ 19 \$$

Erster Anhang: Von den Engeln $\$ 42-43 \ldots . . . . .204$

Zweiter Anhang: Vom Teufel $\$ 44-4 \xi . . . . . . .22 \mathrm{Ix}$

Zweites Lehrstück: Von der Erhaltung $\$ 46-49$. . . . . . . 224

Zweiter Abschnitt: Von den göttlichen Eigenschaften, welche sich auf das fromme Selbstbewußtsein, sofern es das Verhältnis zwischen Gott und der Welt ausdrückt, beziehen $\$$ so- $\$ 6 \ldots \ldots \ldots$...............

Einleitung $\$$ so-s1 . . . . . . . . . . . $25 s$

Erstes Lehrstück: Ewigkeit Gottes $\$ s 2 \ldots . . . . . . .267$

Zweites Lehrstück: Allgegenwart $\$ \$ 3 \ldots . . . . . . . .272$

Zusatz: UnermeBlichkeit ............. 277

Drittes Lehrstück: Allmacht $\$ 54 \ldots . . . . . . .278$

Viertes Lehrstück: Allwissenheit $\S$ ss . . . . . . . . . 289

Anhang: Von einigen anderen göttlichen Eigenschaften $\$, 6 \ldots$ 301

Dritter Abschnitt: Von der Beschaffenheit der Welt, welche in dem frommen Selbstbewußtsein, sofern es das allgemeine Verhältnis zwischen Gott und der Welt ausdrückt, angedeutet ist $\$ \$ 7-6 \mathrm{r} \ldots \ldots . \ldots 307$

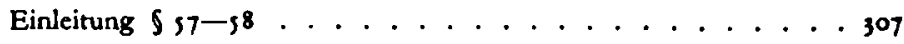

Erstes Lehrstück: Von der ursprünglichen Vollkommenheit der Welt

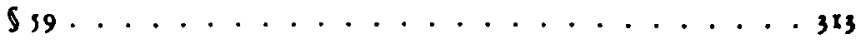

Zweites Lehrstück: Von der ursprünglichen Vollkommenheit des Menschen $\$ 60-61 \ldots . . . \ldots 321$

DER GLAUBENSLEHRE ZWEITER TEIL

Entwicklung der Tatsachen des frommen Selbstbewußtseins, wie sie durch den Gegensatz bestimmt sind $\oint_{6}-1 \sigma_{9} \ldots \ldots \ldots \ldots \ldots \ldots 39$

Einleitung $\$ 62-64 \ldots \ldots \ldots \ldots \ldots \ldots$

Des Gegensatzes erste Seite. Entwicklung des Bewußtseins der

Sünde $₫ 6 s-8, \ldots \ldots \ldots \ldots \ldots \ldots \ldots$

Einleitung $\$ 6 s \ldots \ldots \ldots \ldots \ldots \ldots \ldots$ 
Erster Abschnitt: Die Sünde als Zustand des Menscben \$66-74 355

Einleitung \$66-69 . . . . . . . . . . 35s

Erstes Lehrstück: Von der Erbsünde $\$ 70-72 \ldots . . . . .369$

Zweites Lehrstück: Von der wirklichen Sünde $73-74$. . . . 398

Zweiter Abschnitt: Von der Beschaffenheit der Well in Bezie-

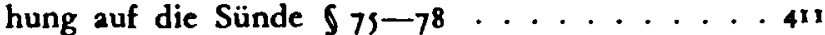

Dritter Abschnitt: Von den göttlicben Eigenschaften, welche sich auf das Bewußtsein der Sünde beziehen $\ 79^{--8}$ \& 424

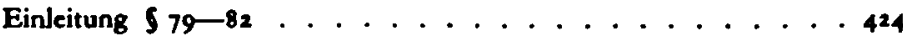

Erstes Lehrstück: Heiligkeit Gottes $\$ 83 . \ldots$. . . . . . . . . 444

Zweites Lchrstück: Gerechtigkeit Gottcs $\$ 84$. . . . . . . . . 449

Anhang: Barmherzigkeit Gottes \$85. . . . . . . . 448

\section{ZWEITER BAND}

Des Gegensatzes andere Seite: Entwicklung des BewuBtseins der

Gnade $\$ 86-169 \ldots \ldots$............. II

Einleitung $\$ 86-90 \ldots \ldots \ldots$ II

Erster Abschnitt: Von dem Zustande des Cbristen, sofern er sich der göttlichen Gnade bewußt ist $\$ 91-112 \ldots 29$

Einleitung $\$ 91 \ldots \ldots 29$

Erstes Haupssfuck: Von Christo \$92-109 . . . . . . . . 31

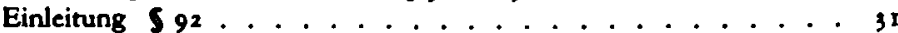

Erstes Lehrstück: Von der Person Christi \$93-95 . . . . . . . 34

Einleitung \$93-99. . . . . . . . . . . . . 34

Erster Lehrsatz $\$ 96 \ldots$

Zweiter Lehrsatz $\$ 97 \ldots \ldots$

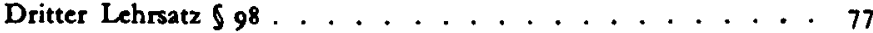

Anhang S99. . . . . . . . . . . . . . . 82

Zweites Lehrstück: Von dem Geschäft Christi $\$ 100-105$. . . . 90

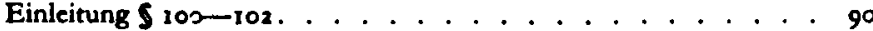

Erster Lehrsatz $\$ 103 . \ldots 108$

Zweiter Lehrsatz: \$ 104. . . . . . . . . . . . . . . . .118

Dritter Lehrsatz $\delta$ ros . . . . . . . . . . . . . 136

Zweites Hauplsstuck: Von der Art, wie sich die Gemeinschaft mit der Vollkommenheit und Seligkeit des Erlösers in der einzelnen

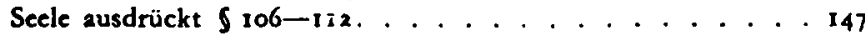

Einleitung $\$ 106 \ldots . . . . . . . . . .147$ 
Erstes Lehrstück: Von der Wiedergeburt $\$ 107-109$. . . . . . 190 Einleitung \$ 107. . . . . . . . . . . Is0 Erster Lehrsatz: \$ $108 \ldots . . . . . . . . . . .193$ Zwciter Lehrsatz: $\$ 109 \ldots \ldots$. . . . . . . . 171

Zweites Lehrstück: Von der Heiligung 110-112 . . . . 182

Einlcitung $\$ 110 \ldots \ldots$. . . . . . . . . 182

Erstcr Lehrsatz: \$111 . . . . . . . . . . . . . 189

Zweiter Lehrsatz: $\$ 112 \ldots . . . . . . . . . .198$

Zweiter Abschnitt: Von der Beschaffenheit der Welt bezüg-

lich auf die Erlösung $\int 111_{3}-163 \ldots 207$

Einleitung $\int 113.114 \ldots 207$

Ersfes Hauptsilick: Von dem Entstehen der Kirche \$115-125 . 215

Einleitung \$11g. $116 \ldots . . . . . . . .21 s$

Erstes Lehrstück: Von der Erwāhlung $\$ 117-120 \ldots . . . . .220$ Einleitung $\$ 117.118 \ldots \ldots 220$ Erster Lehrsatz: $\$ 119 \ldots \ldots$. . . . . . . . . . . . 231 Zweiter Lehrsatz: $\$ 120 \ldots \ldots$ Zusatz . . . . . . . . . . . . . . . . . . 238

Zweites Lehrstück: Von der Mitteilung des heiligen Geistes $121-125248$ Einleitung $\$ 121-122 \ldots \ldots 248$

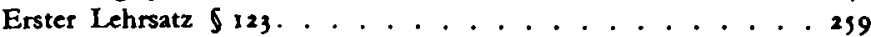
Zweiter Lehrsatz \$124 . . . . . . . . . . . . . . . . 264 Dritter Lehrsatz $\$ 129 \ldots . . . . . . . . . . .270$

Zweites Hauplstuck: Von dem Bestehen der Kirche in ihrem Zusammensein mit der Welt $\$ 126-156 . \ldots 274$

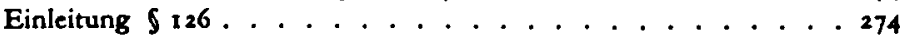

Erste Hälfte: Die wesentlichen und unveränderlichen Grundzüge der Kirche $\{127-147 \ldots \ldots 278$

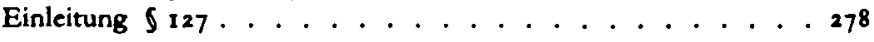

Erstes Lehrstück: Von der heiligen Schrift $128-132 \ldots \ldots$ Einleitung $\$$ 128. $129 \ldots . \ldots 284$ Erster Lehrsatz \$130 . . . . . . . . . . . . 291 Zweiter Lehrsatz $\$ 1$ II . . . . . . . . . . . . . . . . 299 Zusatz $\$ 132 \ldots \ldots \ldots 304$

Zweites Lehrstück: Vom Dienst am göttlichen Wort $\$ 133-133 . . .308$

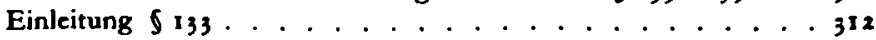
Erster Lehrsatz \$134. . . . . . . . . . . . . . . . . . 312 Zweiter Lehrsatz \$13s. . . . . . . . . . . . . . 315

Drittes Lehrstück: Von der Taufe $\$ 136-138 \ldots . . . . . . .318$ Einleitung $\$ 136 \ldots \ldots$. . . . . . . . 318

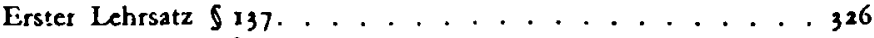
Zwciter Lehrsatz \$138 . . . . . . . . . . . . 33\$ 
Viertes Lehrstück: Vom Abendmahl $\$ 139-142 \ldots . . . . .340$

Einleitung $\$ 139-140 \ldots . . \ldots 340$

Erster Lehrsatz \$141............... . . . . . . . . . . . .

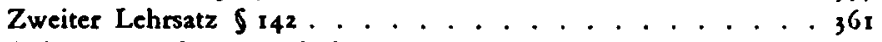

Anhang zum dritten und vierten Lehrstück: $\$ 143 \ldots . . .363$

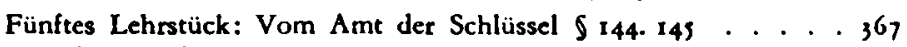

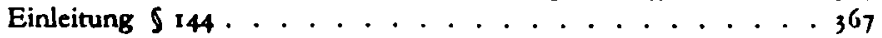

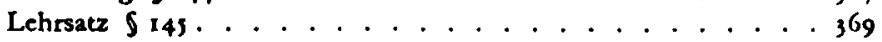

Sechstes Lehrstück: Vom Gebet im Namen Jesu $\$ 146.147$. . 376

Einleitung $\$ 146 \ldots . . \ldots . . . . . .376$

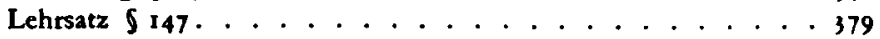

Zweite Hälfte: Das Wandelbare, was der Kirche zukommt vermöge ihres Zusammenseins mit der Welt $\ 14^{8-156 . \ldots . . . ~} 384$

Einleitung \$148.149.............. . 384

Erstes Lehrstück: Von der Mehrheit der sichtbaren Kirche in bezug auf die Einheit der unsichtbaren $\int 150-1$ 152 . . . . 391

Einleitung $\$ 150 \ldots \ldots$. . . . . . . . 391

Erster Lehrsatz $\ 1$ I 1. . . . . . . . . . . . . . . . 393

Zweiter Lehrsatz $\$ y,z . . . . . . . . . . . . . 395

Zweites Lehrstück: Von der Irrtumsfähigkeit der sichtbaren Kirche in bezug auf die Untrüglichkeit der unsichtbaren $\$ 153-155.398$

Einleitung $\$ 153 \ldots \ldots . \ldots . \ldots . \ldots 39$

Erster Lehrsatz $\$ 1$ 154. . . . . . . . . . . . . . . . . 400

Zweiter Lehrsatz $\$ Is . . . . . . . . . . . . . . . 402

Zusatz zu beiden Lehrstücken $\$ is6. . . . . . . . . 404

Dritles Haupistiuck: Von der Vollendung der Kirche $\int 157^{-1} G_{3} .+408$

Einleitung $\$$ is7-1\$9 . . . . . . . . . . . . 408

Erstes prophetisches Lehrstück: Von der Wiederkunft Christi $\$$ IGo 421

Zweites prophetisches Lehrstück: Von der Auferstehung des Fleisches

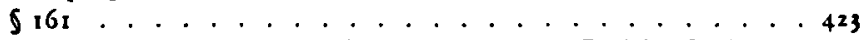

Drittes prophetisches Lehrstück: Vom jüngsten Gericht $\oint_{162}$. 429

Viertes prophetisches Lehrstück: Von der ewigen Seligkeit $₫ 163 .+433$

Anhang: Von der ewigen Verdammnis . . . . . . . . . 437

Zusatz zu den prophetischen Lehrstücken ........ 439

Dritter Abschnitt: Von den göttlichen Eigenschaften, welche sich auf die Erlösung beziehen $\oint_{164-169} \ldots . .441$

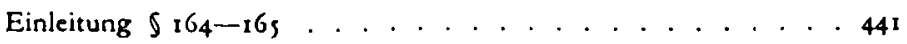

Erstes Lehrstück: Von der göttlichen Liebe $\$ 166.167 . \ldots 46$

Einleitung $\$ 166 \ldots . \ldots . \ldots . \ldots 46$

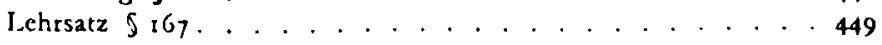

Zweites Lehrstück: Von der görtlichen Weisheit $\$ 168.169 . .451$

Einlcitung $\$ 168 \ldots \ldots$. . . . . . . . . 45

Lehrsatz $\$ 169 . \ldots . . . \ldots . . . . . . . . .45 s$ 
Schluß: Von der göttlichen Dreiheit $\$ 170-17^{2} \ldots \ldots . \ldots 5^{8}$

Anhang des Herausgebers

Vergleichendes Register der Seitenzahlen der 2.-7. Auflage . . 476

Synopse der Leitsätze der I. und 2. Auflage mit bisher unver-

öffentlichten Zusätzen aus Schleiermachers Kollegheft . • 497

Verzeichnis der Personen.............. . . 564

Verzeichnis der Bibelstellen. . . . . . . . . . . . 666

Verzeichnis der wichtigsten Stichwörter......... $7^{2}$ 